\title{
The Effect of 20-20-20 Rule Dissemination and Artificial Tears Administration in High School Students Diagnosed with Computer Vision Syndrome
}

\author{
Bambang Subakti Zulkarnain ${ }^{1 *}$, Rozalina Loebis ${ }^{2}$, Aniek Setiya Budiatin', Toetik Aryani ${ }^{1}$ \\ ${ }^{1}$ Department of Clinical Pharmacy, Faculty of Pharmacy, Universitas Airlangga, Surabaya, Indonesia \\ ${ }^{2}$ Department of Ophthalmology, Faculty of Medicine, Universitas Airlangga, Surabaya, Indonesia
}

Submitted: February 08 ${ }^{\text {th }}$ 2020; Revised: December 02 ${ }^{\text {nd }}$ 2020; Accepted: January $08^{\text {th }} 2021$

Keywords:
Education
20-20-20 rule
Computer vision
syndrome
Gadget
High school
students
Artificial tear

\begin{abstract}
Computers and gadgets are modern tools for assisting Senior High School students' work. However, using gadgets more than 2 hours a day may cause computer vision syndrome (CVS), which can interfere with academic activities. CVS main symptom is dry eyes. CVS could be prevented by applying the 20-20-20 rule and artificial tears. A total of 100 students from two public high schools in Kediri with 50 students from each school were selected for this community service. All students diagnosed with CVS participated in the dissemination of 20-20-20 rule and artificial tear administration. The pre-test and post-test scores, the Tear Break Up Time Test (TBUT) and the Ocular Disease Surface Index (OSDI) were measured within two weeks. TBUT and OSDI are parameters for measuring dry eye. Likewise, interviews were conducted to assess the adherence to the 20-20-20 rule and artificial tea administration. The results showed the knowledge level increased ( $p<0.0001)$. Most students understood 20-20-20 rule and how to administer artificial tears correctly. However, the adherence to both methods was approximately $50 \%$. There was an improvement in the TBUT ( $p<0.0001)$ for dry eyes but not for OSDI ( $p>$ 0.05 ). Applying the $20-20-20$ rule and artificial tears could be used for CVS treatment.
\end{abstract}

\section{INTRODUCTION}

Computer and gadget users in Indonesia range from toddlers to the elderly (Novitasari \& Khotimah, 2016). The number of internet users in Indonesia increased in 2019, reaching 171,260,000 (Internet World Stats, 2019). It is due to the benefits computer and gadgets provide for human life to increase the efficiency of time, cost, and energy. Not only the number of users is increasing, but the time spent on the gadget is also much longer.

Despite the positive impact, computers and gadgets also bring negative impacts. One of them is the radiation effect caused by the prolonged gadget use.
The light emitted harms the eyes, mainly in prolonged use. High Energy Visible (HEV) light, commonly known as blue light, is a powerful light emitted by a gadget, which can cause cataracts and age-related macular degeneration (AMD) (The Vision Council, 2014).

Almost $90 \%$ of computer users have vision and eye issues, such as headaches, eye fatigue, eye strain, dry eyes, double vision, and blurred vision (Alghamdi \& Alrasheed, 2020). Loebis (2017) stated that the prolonged use of gadgets (mobile devices, such as cellphones) could cause eye problems such as Computer Vision Syndrome (CVS). It is mainly caused

ISSN 2460-9447 (print), ISSN 2541-5883 (online)

*Corresponding author: Bambang Subakti Zulkarnain

Department of Clinical Pharmacy, Faculty of Pharmacy, Universitas Airlangga, Nanizar Jaman Joenoes Building Campus C Unair, Surabaya, 60115 Indonesia

Email: bambang-s-z@ff.unair.ac.id 
by dry eye disease (DED) (Blehm et al., 2005). Reddy et al. (2013) stated that computer use for more than two hours a day is a CVS risk factor.

CVS or digital eye strain is a current rising public health problem. Approximately 60 million people suffer from CVS globally (Sen \& Richardson, 2007; Alghamdi \& Alrasheed, 2020). The worldwide CVS prevalence CVS is estimated to be $25 \%-93 \%$ (Blehm et al., 2005). In Malaysia, the CVS prevalence reaches almost $90 \%$ among young adults, specifically students (Reddy et al., 2013). Meanwhile, in Indonesia, the number is not yet known. However, it is estimated to be almost similar to other countries.

Alghamdi \& Alrasheed (2020) stated that CVS reduces work productivity, increases work errors, affects job satisfaction, and impairs vision. While for high school students, CVS can interfere with their academic activities due to impaired vision. A study explained that DED, main cause of CVS, causes problems in several daily activities, such as reading (OR 3.64; 95\% CI 2.45-5.40; p <0.0001); doing professional work (OR 3.49; 95\% CI 1.72-7.09; p $<0.001$ ); using a computer (OR 3.37; 95\% CI 2.11-5.38; $\mathrm{p}<0.0001$ ); watching television (OR 2.84; 95\% CI 1.05-7.74; $\mathrm{p}=0.04$ ); driving during the day (OR 2.80; $95 \%$ CI 1.58-4.96; $\mathrm{p}<0.0001$ ); and driving at night (OR 2.20; 95\% CI 1.48-3.28; $\mathrm{p}<0.001$ ) (Miljanovic et al., 2007).

CVS can cause evaporative DED (evaporating tears) due to screen time. DED can be treated by administering artificial tears solution. It replaces the evaporating tears and replenishes the tear film (LAM). Pucker et al. (2016) said that artificial tears replace the tears layering the cornea and conjunctiva's surface. Artificial tears solution is safe and effective for DED. There are various forms of artificial tears solution. They can be obtained freely on the market, but some artificial tears require a doctor's prescription. Besides, 20-20-20 rules should be applied. It is a technique when every 20 minutes being in front of a screen, resting your eyes by closing them for 20 seconds, or seeing as far as 20 feet (6 meters). The result of Alghamdi \& Alrasheed's (2020) study shows that applying 20-20-20 technique can overcome the DED symptoms and improve the eye surface integrity.

A tear film break-up time (TBUT) examination procedure was used to detect DED (Kumar et al., 2014). TBUT is the time the tear film (LAM) takes to burst in the blink of an eye. TBUT is a parameter to assess the stability of the LAM. TBUT for healthy eyes is $15-20$ seconds, while TBUT for DED is less than 10 seconds. Elvira \& Wijaya (2018) stated that the TBUT in dry eyes is $5-10$ seconds. The TBUT examination procedure was carried out by lubricating LAM using fluorescein. The patient should not blink their eyes, and then it is observed using cobalt on a slit lamp. LAM breakdown time occurs when dry spots appear in the cornea's fluorescein layer (Eva \& Augsburger, 2018). DED diagnosis can also be obtained using a questionnaire, such as the Ocular Surface Disease Index (OSDI), which is frequently used. This questionnaire is already validated and can be applied in various clinical trials (Schiffman et al., 2000).

Children stares the computer longer in a day both at home and school. It can increase the risk of early myopia (Wimalasundera, 2006). In the last five years, the time spent in front of the computer in the 8-18-year age group increased from 1 hour per day to 1.5 hours per day on weekdays. It is also followed by an increasing number of internet users, age 8-18 years old, who seek entertainment (Rideout et al., 2010).

Good eyesight is needed to support academic success, especially at the age of 6-18 years. Impaired vision will reduce the skills needed in children's education (American Optometric Association, 2018). $80 \%$ of students aged 16 years in Sweden spend three hours per day in front of the screen (Hedendahl et al., 2017). Moreover, in Korea, the number of eye problems in young adults who spend more than two hours in front of screen increases, so does the vision symptoms (Jaiswal et al., 2019). Therefore, there is a tendency for high school students aged 15-18 years to develop CVS due to the use of gadgets.

Understanding the use of artificial tears and its advantage, also applying the 20-20-20 technique to high school students will be very useful for dealing with DED and CVS, especially in this pandemic situation when most activities are conducted online. Therefore, this community service is expected to enrich the participants' knowledge of CVS caused by DED and its prevention by implementing the 20-20-20 rule.

\section{METHOD}

This community service was conducted in two stages; the initial stage (pre) and the final stage (post). The first stage was dissemination on the advantage of 20-20-20 rules, CVS check through TBUT examination and OSDI questionnaire by an ophthalmologist, and distribution of artificial tears and its usage procedure for those diagnosed with CVS. The presentation emphasized the 20-20-20 rule implementation. The result was then evaluated, including questions related to symptoms, CVS risk factors, 20-20-20 rules, body posture, main therapy, other therapies, use of CVS medicines, and CVS nutrition. This activity obtained the preliminary data for TBUT and OSDI students.

The last stage was conducted two weeks after the distribution of artificial tears, considering the healing time for corneal wounds, which is around ten days (Lee, 
2016). Therefore, a two-week lag was used to assess improvement in TBUT and OSDI in students. In this stage, TBUT and OSDI checks were carried out. Before that, the students were interviewed related to medicine consumption and 20-20-20 rules.

\section{RESULT AND DISCUSSION}

The technological revolution increases the use of smart digital tools, which ease the works. However, CVS can harm the eyes due to the long screen time. The result shows that $93 \%$ of students in two public high schools in Kediri suffered from CVS. It is quite similar to Malaysia's case and CVS global prevalence, which is around 90\% (Reddy et al, 2013; Alghamdi \& Alrasheed, 2020). The main symptom of CVS is DED, which can be treated by applying 20-20-20 rule and the administration of artificial tears. The success rate is determined by the TBUT and OSDI scores.

\subsection{High School Students Knowledge toward CVS and Interview Result on the Evaluation of Implementation}

The dissemination on CVS prevention and the therapy was attended by 50 students of SMAN 1 Kediri and 50 SMA N 3 Kediri. The presentation emphasized the use of artificial tears and the 20-20-20 rule. Students answered the same questions for pre-test and post-test, which contain ten questions related to the presentation. They were CVS symptoms, CVS risk factors, 20-20-20 rules, body posture in front of a computer, artificial tear main therapy for CVS, other therapy classes, how to consume medicine, and nutrition for CVS. The assessment was carried out by determining the correct answers (the lowest score is 0 and the highest score is 10). The assessment result is presented in Figure 1.

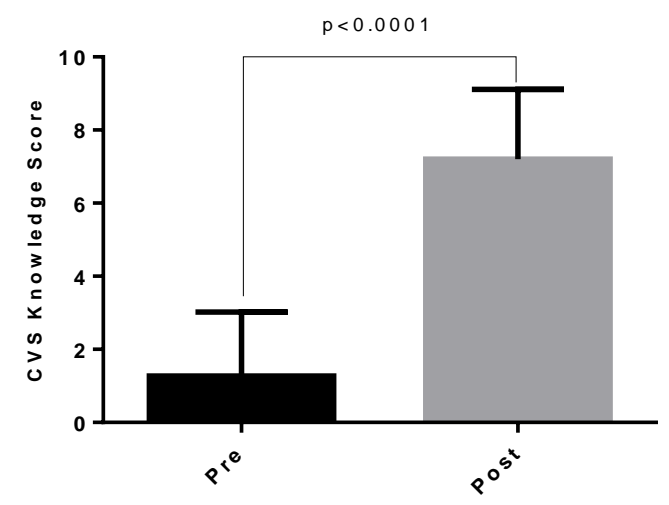

Figure 1. The result score among SMAN 1 and SMA N 3 students

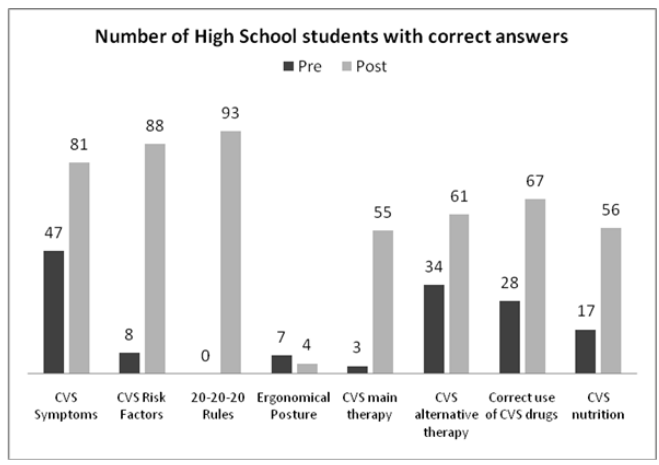

Figure 2. Students answer distribution for pre-test and posttest

Figure 1 shows an increasing trend in the total score of students' knowledges $(\mathrm{p}<0.0001)$. It shows that students understand the material given during the presentation. Furthermore, Figure 2 shows an increasing number of students who correctly answer the 20-20-20 rules, from 0-93 students. Reddy et al. (2013) stated that the 20-20-20 rule technique could be used to prevent CVS. Experimental studies on CVS patients at Qassim University show that 20-20-20 rules can reduce DED symptoms (Alghamdi \& Alrasheed, 2020). Similar experimental research conducted in Indonesia by Anggrainy et al., (2020) also shows that 20-20-20 rules can reduce CVS symptoms. Thus, the 20-20-20 rule is a non-pharmacological technique to treat CVS symptoms.

Pre-test and post-test results (Figure 2) showed an increase of student number who understood that the main therapy in DED and CVS is artificial tear (3 vs 55 students). DED that was properly handled would affect CVS. Pucker et al. (2016) stated that OTC artificial tear is safe and effective to cure DED. This is based on a literature study that showed that all artificial tear types have similar effectivity (Pucker et al., 2016). In this activity, the procedure on using artificial tear was shown in a short video. This was conducted based on Feng et al. 's (2016) opinion, which explained that using video as a medium to explain the procedure to use artificial tears could increase participants understanding of the subject. This strategy successfully increased the number of participants who understood the procedure of using CVS medicine, from 28 students to 67 students (Figure 2).

Before the second TBUT and OSDI examinations (post), interviews were conducted to students to check their understanding. The results suggested that an average of $50 \%$ of students practiced the 20-20-20 rule and the procedure of using artificial tears properly. This number is relatively low. Similar results were obtained by Swanson (1998) in his research about adherence in using artificial tear, which showed that the percentage of people with DED who obeyed the procedure and routinely used the medicines were only $63 \%$. Swanson (1998) argued that this number is in line with the 
characteristics of the population studied. The characteristic of the population in Swanson (1998) study is a mixture of various individuals diagnosed with mild to severe DED.

Adherence would increase if the population studied only included a severe DED population. It should also be noted that the causes of DED can be differentiated into evaporation-induced DED and tear film reduction-induced DED. In the high school age group, which is generally around 16-18, tear film production is still good. They suffered from evaporation-induced DED after being exposed to gadget light radiation. DED among their age is usually mild to medium, although there are some severe cases too, such as the injured cornea. This suggests that artificial tear application among high school students is still low.

The number of students who applied 20-20-20 rule $(50 \%)$ is considered relatively low despite the increasing number of students who understood the rule (Figure 2). Al Tawil et al. (2020) stated that knowledge level does not correlate with the practice or application of the knowledge received. As many as $63 \%$ of the population in Al Tawil et al. (2020)'s study who experienced all the three CVS symptoms also understood the 20-20-20 rule. Nonetheless, 20-20-20 rule is still important in CVS handling procedure. A Study conducted by Anggrainy et al., (2020) showed the success of 20-20-20 rule to prevent CVS among the study respondents. Similarly, Alghamdi \& Alrasheed (2020)'s study also suggested that 20-20-20 rule education can prevent CVS.

An interesting point illustrated in Figure 2 is the body posture to prevent CVS. Ergonomic position for gadgets can significantly affect CVS prevalence. Positioning the gadget below eye level can reduce CVS risk. This study result by Mowatt et al. (2017) about the effect of ergonomic position on the CVS showed that positioning gadgets below eye level can reduce ocular discomfort symptoms and neck pain experienced by people with CVS. Hence, CVS symptoms prevalence among college students can be prevented by improving ergonomic position while using the gadget.

\subsection{Tear Break Up Time Test (TBUT)}

The main symptom of CVS is dry eyes or DED. Dry eyes can be examined with TBUT clinical testing. TBUT can examine the stability of tear film. Tear film is formed in one blink. TBUT measures how long tear film lasts (stable) before it finally breaks. Normal TBUT time is $>10$ seconds. In the early examination (pre), the average TBUT score among students is 5 seconds. After an artificial tear was applied, the TBUT score reached 8 seconds. The results of 20-20-20 rule learning session and artificial tear application suggested that there is an improvement of tear film stability even though the score has not reached the normal value of more than 10 seconds (Figure 3).

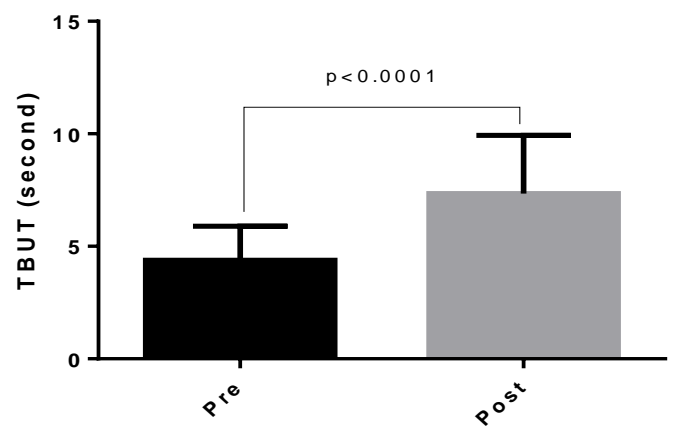

Figure 3. Tear Break up Time Test (TBUT) among high School students before and after 20-20-20 rule dissemination and administering artificial tear solution

When using a computer for a long time, the TBUT score will decrease. Akkaya (2018) stated that using a computer more than eight hours a day will decrease TBUT due to evaporation-induced DED. The purpose of administering artificial tear solution is to restore tear film stability in DED. Tears film consists of three layers, which are lipid, aqueous, mucous layers. Santos et al. (2011) compared the application of three types of artificial tears solutions that work in each tear film layer. The results showed that there was no effectivity difference between those three artificial tear solutions. All three solutions could increase TBUT score indicated by the results of pre vs post TBUT tests $(\mathrm{p}<0.0001)$. The results are illustrated in Figure 3 of this paper.

\subsection{OSDI Score}

OSDI (Ocular Surface Disease Index) is a standard questionnaire to examine dry eyes, consisting of 12 questions with 0-100 score range to measure the severity level of dry eyes. According to OSDI interpretation, 0-12 score means normal dry eyes, 1322 is mild, 23-32 is moderate, and above 33 is severe (Schiffman et al., 2000).

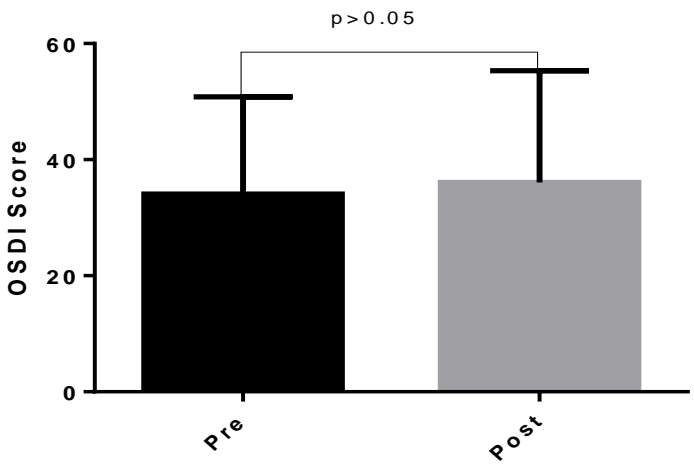

Figure 4. Ocular Surface Disease Index (OSDI) among high school students before and after 20-20-20 rule dissemination and artificial tear solution administration 
In Figure 4, it can be seen that the OSDI score shows no significant difference before and after the dissemination of 20-20-20 rule and the administering of artificial tear solution $(p>0.05)$. Those OSDI scores indicate that the DED level pre vs post 20-20-20 rule dissemination and artificial tear solution application is in the severe category. The administering of artificial tears should be able to decrease OSDI scores. Santos et al. (2011) research showed a decrease of OSDI score in a comparative study regarding the use of artificial tear solution in thirty days. It showed that artificial tear solution should be used continuously for thirty days and accompanied by 20-20-20 rule application in order to reduce the OSDI score.

\section{CONCLUSION}

CVS dissemination, which emphasizes 20-20-20 rule application, and the correct use of artificial tear (dropping method and frequency) can increase TBUT score among the students of SMAN 1 and SMAN 3 Kediri. This increase indicates improved dry eyes symptoms and a reduced number of students with CVS, even though the score did not reach normal TBUT rate. Adherence assessment on the 20-20-20 rule and artificial tear application that were not carried out with existing adherence instrument becomes a limitation of this community service and an opportunity that both actions above can potentially return TBUT to normal quickly because young people in high school level still have normal tears production. Around 4-6 students who stated in the preliminary interview that they periodically close their eyes while using a computer and gadget, despite not knowing about 20-20-20 rule, turned out to have a TBUT score above 10 seconds (normal). Based on this community service result, 2020-20 rule should be disseminated in every education level to prevent CVS, especially during this COVID-19 pandemic where learning activities are carried out online. Artificial tear solution should be applied after consultation with competent doctors, and its use should be accompanied with 20-20-20 rule to accelerate dry eyes prevention so that the TBUT can return to normal faster.

\section{ACKNOWLEDGMENT}

We would like appreciate and express our gratitude to the Faculty of Pharmacy and Faculty of Medicine, Airlangga University, and all teachers and employees of SMAN 1 and SMAN 3 Kediri.

\section{REFERENCE}

Akkaya, S., Atakan, T., Acikalin, B., Aksoy, S., \& Ozkurt, Y. (2018). Effects of long-term computer use on eye dryness. Northern clinics of Istanbul, 5(4), 319-322. DOI: 10.14744/nci.2017.54036
Antari, N.P.U \& Putra, A.S. (2014). Tingkat Pengetahuan tentang Penanganan Obat dalam Swamedikasi dan Pengaruhnya terhadap Kebiasaan Menggunakan Obat pada Respoden di Apotek Gunung Sari [Skripsi]. Denpasar: Akademi Farmasi Saraswati.

Alghamdi \& Alrasheed. (2020). Impact of an educational intervention using the 20/20/20 rule on Computer Vision Syndrome. African Vision Eye Health, 79(1), a554. DOI: https://doi.org/10.4102/aveh.v79i1.5 54

Al Tawil L, Aldokhayel S, Zeitouni L, Qadoumi T, Hussein S, Ahamed SS. (2020). Prevalence of self-reported computer vision syndrome symptoms and its associated factors among university students. European Journal of Ophthalmology, 30(1), 189195. DOI: $10.1177 / 1120672118815110$

American Optometric Association. (2018). Computer Vision Syndrome. https://www.aoa.org/patientsand-public/caringfor-yourvision/protectingyour-vision/computervision-syndrome

Anggrainy, Lubis, \& Ashar, P., Lubis, R., \& Ashar, T. (2020). The effect of trick intervention 20-20-20 on computer vision syndrome incidence in computer workers. Journal of Ophtalmology (Ukraine), 432(1), 27. DOI:10.31288/oftalmolzh202012227

Blehm et al. (2005). Computer Vision Syndrome: A Review. Survey of Ophthalmology, 50(3), 253262. DOI: 10.1016/j.survophthal.2005.02.008

Elvira \& Wijaya, V.N. (2018). Penyakit Mata Kering. CDK Edisi Suplemen, 193-194.

Eva, P.R. \& Augsburger, J.J. (2018). Vaughan \& Asbury's General Ophtalmology (19th edition). New York: Mc Graw-Hill Education.

Feng, A., John O, Mitchell H, Catherine G, Martha MW, \& Sandra RM. (2016). Success of patient training in improving proficiency of eyedrop administration among various ophthalmic patient population. Clinical Ophthalmology, 10, 5051511. DOI: $10.2147 /$ OPTH.S108979

Hedendahl, LK., Michael C, Tarmo K, \& Lennart H. (2017). Measurements of Radiofrequency Radiation With A Body-Borne Exposimeter In Swedish Schools With Wi-Fi. Frontiers in Public Health, 5, 279. DOI: $10.3389 /$ fpubh.2017.00279

Internet World Stats. (2019). https://www.internetworlstats .com/stats3. htm, 23 September 2019.

Jaiswal, S., Asper, L., Long, J., Lee, A., Harrison, K., \& Golebiowski, B. (2019). Ocular and visual discomfort associated with smartphones, tablets and computers: what we do and do not know. Clinical \& experimental optometry, 102(5), 463- 
Kumar, P., Bhargava, R., Kaur, A., Kumar, M., \& Mishra, A. (2014). The diagnostic value and accuracy of conjunctival impression cytology, dry eye symptomatology, and routine tear function tests in computer users. Journal of laboratory physicians, 6(2), 102108. DOI: $10.4103 / 0974-2727.141507$

Lee. (2016). The Ins and Outs of Corneal Wound Healing. https://www.reviewofoptometry.com/article/the -ins-and-outs-of-corneal-wound-healing May 2, 2019

Loebis, R. (2017). Effects of computer and mobile devices usage on visual acuity and tear film in children [E-Poster]. 32nd Asia Pasific Academy of Ophthalmology Congress, Singapore.

Miljanović, B., Dana, R., Sullivan, D. A., \& Schaumberg, D. A. (2007). Impact of dry eye syndrome on vision-related quality of life. American journal of ophthalmology, 143(3), 409-415. DOI: 10.1016/j.ajo.2006.11.060

Mowatt, L., Gordon, C., Santosh, A., \& Jones, T. (2018). Computer vision syndrome and ergonomic practices among undergraduate university students. International journal of clinical practice, 72(1). DOI: 10.1111/ijcp.13035

Novitasari, W. \& Khotimah, N. (2016). Dampak Penggunaan Gawai terhadap Interksi Sosial Anak Usia 5-6 Tahun. Jurnal PAUD Teratai, $5(3), 1-2$.

Pucker, A.D. et al. (2016). Over the counter (OTC) artificial tear drops for dry eye syndrome. Cochrane Database of Systematic Reviews 2016, Issue 2. Art. No.: CD009729.

Reddy, S.C. et al. (2013). Computer vision syndrome: a study of knowledge and practices in university students. Nepal Journal of Ophthalmology, 5(3), 161-168. DOI: 10.3126/nepjoph.v5i2.8707

Rideout, V.J. et al. (2010). Generation M2 Media In The Lives of 8-To 18-Year Olds. A Kaiser Family Foundation Study, p. 20.

Santos C., G., Borges, C., Nunes, S., Salgado-Borges, J., \& Duarte, L. (2011). Efficacy of 3 different artificial tears for the treatment of dry eye in frequent computer users and/or contact lens users. European journal of ophthalmology, 21(5), 538544. DOI: 10.5301/EJO.2011.6324

Schiffman, R. M., Christianson, M. D., Jacobsen, G., Hirsch, J. D., \& Reis, B. L. (2000). Reliability and validity of the Ocular Surface Disease Index. Archives of ophthalmology (Chicago, Ill. : 1960), 118(5), 615621. DOI: 10.1001/archopht.118.5.615

Sen, A. \& Richardson, S. (2007). A study of computerrelated upper limb discomfort and computer vision syndrome. Journal of Human Ergology, 36(2), 45-50.
Swanson M. (1998). Compliance with and typical usage of artificial tears in dry eye conditions. Journal of the American Optometric Association, 69(10), 649-655.

The Vision Council. (2014). Digiteyezed: The Daily Impact Of Digital Screens On The Eye Health Of Americans. Diakses dari https://www.thevisioncouncil.org/

Wimalasundera, S. (2006). Computer Vision Syndrome. Galle Medical Journal, 11(1), 26. DOI: http://doi.org/10.4038/gmj.v11i1.1115 